\title{
RATE OF GAIN AND SATIETY IN EARLY INFANCY
}

\author{
BY
}

\author{
IAN G. WICKES \\ From the Children's Department, St. Bartholomew's Hospital, London
}

(RECEIVED FOR PUBLICATION FEBRUARY 22, 1952)

' Infants give no light into the knowledge of their diseases other than what we are able to discover from their uneasy cries.'-Walter Harris (1689).

Soon after the war a follow-up clinic for infants born in the maternity ward was re-established at St. Bartholomew's Hospital, the intention being that each infant should attend on one occasion during the second month of life for review. It soon became apparent that the progress of most infants had already been checked either by inadequate lactation or by the active limitation of the size of their feeds. To make matters worse, about one infant in every seven had suffered an actual reduction in the size of the feeds to limit a rate of gain in weight which had been considered excessive, or to treat such symptoms as crying and vomiting which had been erroneously attributed to overfeeding. In most cases this reduction in intake resulted in the development of obvious hunger or served to aggravate the symptoms already present. In consequence many mothers had rejected the advice given at the infant welfare clinic, whose reputation had thereby suffered.

The purpose of this paper is to establish a figure for the average rate of gain in the first two months of life, to show that it is desirable and safe to encourage infants to exceed this average rate, and to demonstrate how far present-day feeding methods fall short of the ideals at which we should aim. In order to do this a consecutive series of 503 potentially healthy infants has been studied and an opportunity has arisen for comparing the progress of a selected group with an unblemished feeding history with the remainder whose rate of gain has been checked by underfeeding, recognized or unrecognized and actively or passively applied. It is significant that this selected group comprised less than half the total series, and there are good reasons for believing that it still contains some infants who would have thrived more satisfactorily on a self-regulated intake. Indeed, Illingworth's (1949) dictum that most feeding difficulties are man-made has been amply confirmed.
Previous Investigations

Previous investigations into the rate of gain in weight in infancy have embraced the first six months of life or longer and the literature contains no reference to the peculiarities found in the first trimester as compared with the second. There has been a general tendency to iron out the irregularities, and thus the special features of the growth curve in the early weeks have been almost entirely disregarded. Yet this first three months is a critical period both for mental and physical development and for the absorption of the newborn infant, welcome or otherwise, into the family group. In this study attention has therefore been focused on the infant's progress to the end of the second month, thus covering the period when feeding difficulties most commonly occur.

Recent reports agree that the normal infant gains weight at the rate of 6 to $7 \mathrm{oz}$. weekly in the first three months (Sontag and Reynolds, 1945; Boyd, 1948 ; Gore and Palmer, 1949). However, these investigations, in which the early weeks merge imperceptibly with the curve up to school age, have not concentrated on the period under review here and they fail to show what setbacks had occurred due to birth trauma, neonatal diseases and subsequent feeding difficulties, whereas the present investigation indicates that the growth of more than half the infants in the series has been checked for some of these reasons before the end of the second month.

Before the publication of recent figures for weight curves in infancy smaller rates of gain have been accepted as normal. Thus Feldman (1927) regarded the average gain between the first and third month as 5 oz. per week, and in Hutchison's lectures (1944) we find in italics that ' the average weekly gain in weight is $4 \frac{1}{2}$ to $6 \mathrm{oz}$.' for infants from the first fortnight to the sixth month. Furthermore, Morris (1947) in Paterson and Moncrieff's edition of Garrod, Batten and 
Thursfield's Diseases of Children stated that during the first six months the weekly increase in weight amounts to $5 \mathrm{oz}$., and Collis (1948) records without qualification that the average gain per week is 4-6 oz. Since there is a tendency to regard such figures as an optimum to be achieved rather than an average to be surpassed, it will be seen why feeding difficulties loom so large in the feeding histories of early infancy. Spock (1946) approaches nearest to reality when he regards the average rate for the first three months as 7-8 oz. per week, but it will be seen that this figure is probably still too low.

\section{Present Investigation}

At St. Bartholomew's Hospital primiparae who register early enough are accepted by the maternity department and all multiparae in whom obstetrical difficulties are expected, who are known to be carrying twins, or who are suffering from pulmonary tuberculosis, rheumatic heart disease, diabetes, etc., are admitted to the ward.

The present series comprises 503 infants born to 366 primiparae and 125 multiparae. Six of the former and 10 of the latter carried twins but one from two pairs from each group died. The surviving infants may be regarded as potentially normal babies from the point of view of feeding and growth, but three abnormals, one mongol and two with cleft palates, have been excluded. No doubt also some of those who failed to attend the follow-up clinic defaulted because they were sick.

On discharge from the maternity ward all available mothers were given appointments to attend the follow-up clinic and $85 \%$ kept them. Furthermore $80 \%$ of the first babies and $66 \%$ of the others had already attended their local infant welfare clinic on at least one occasion before returning to the hospital.

At the first interview in the follow-up clinic a separate form for each infant giving the feeding history and the necessary details for the calculation of the rate of gain was completed. All mothers were asked whether their baby had ever been regarded as underfed or overfed, and whether or not he was at present satisfied with his feeds.

The ages at which the infants first attended the clinic are listed below:

\begin{tabular}{c|c}
\hline Age (to nearest week) & Number of Infants \\
\hline 4 & 20 \\
5 & 43 \\
6 & 97 \\
7 & 200 \\
8 & 116 \\
9 & 27 \\
\hline & Total 503 \\
\hline
\end{tabular}

Table 1 summarizes these 370 babies born to primiparae and 133 born to multiparae with respect to sex and birth order.

TABLE 1

SEX AND BirTh ORder IN 503 INFANTS

\begin{tabular}{|c|c|c|c|c|c|}
\hline \multirow{3}{*}{ Sex } & \multicolumn{5}{|c|}{ Number of Infants } \\
\hline & \multicolumn{4}{|c|}{ Birth Order } & \multirow{2}{*}{ Total } \\
\hline & 1 & 2 & 3 & $\begin{array}{c}4 \text { or } \\
\text { higher }\end{array}$ & \\
\hline $\begin{array}{l}\text { Male } \\
\text { Female }\end{array}$ & $\begin{array}{l}190 \\
180\end{array}$ & $\begin{array}{l}53 \\
38\end{array}$ & $\begin{array}{l}16 \\
13\end{array}$ & $\begin{array}{l}8 \\
5\end{array}$ & $\begin{array}{l}267 \\
236\end{array}$ \\
\hline
\end{tabular}

Rate of Gain in Weight

When studying the feeding histories of young infants it is logical to measure the rate of gain from the time the birth weight was regained, for in this way early set-backs, complicated deliveries and other difficulties are largely eliminated. This point is of particular importance here as the multiparae were selected for obstetrical reasons. As many of the infants had not in fact regained their birth weight when they left the ward an estimation of this time interval has been made by assuming a rate of gain of $1 \mathrm{oz}$. daily from the day they reached home until the deficit in weight had been made up. It was unfortunate that this procedure had to be adopted in $34 \%$ of the whole group, but as none of the infants were more than a few ounces below their birth weight on discharge it is thought that little inaccuracy has been introduced. In any case the weighing of infants in itself is by no means accurate, depending as it does upon the proximity of a feed and the contents of the rectum and bladder. The effect of assuming a rate of gain of $1 \mathrm{oz}$. daily has been to lower the average rate in those who had gained less, and to raise it in those who had gained more, but the error introduced in this way is very small.

Table 2 sets out the number of infants who regained their birth weights at various ages; for those in the right-hand column the estimation as described above had been carried out. The necessary data were missing in two cases.

TABLE 2

Age of Regaining BiRth Weight in 501 INfants

\begin{tabular}{|c|c|c|c|c|}
\hline \multicolumn{5}{|c|}{ Number of Infants } \\
\hline \multirow{2}{*}{\multicolumn{3}{|c|}{ Birth Weight Regained }} & \multicolumn{2}{|c|}{ Discharge Weight } \\
\hline & & & $\begin{array}{c}\text { Over Birth } \\
\text { Weight }\end{array}$ & $\begin{array}{c}\text { Under Birth } \\
\text { Weight }\end{array}$ \\
\hline \multirow[t]{2}{*}{$\begin{array}{l}\text { On or before 3rd day } \\
\text { From 4th-7th day } \\
\text { From 8th-11th day } \\
\text { From 12th-15th day } \\
\text { From 16th-19th day } \\
\text { On or after 20th day }\end{array}$} & $\begin{array}{l}\cdots \\
\cdots \\
\cdots \\
\cdots\end{array}$ & $\begin{array}{l}. \\
\therefore \\
\cdots \\
\cdots\end{array}$ & $\begin{array}{r}7 \\
89 \\
168 \\
44 \\
13 \\
9\end{array}$ & $\begin{array}{l}- \\
\overline{11} \\
91 \\
43 \\
26\end{array}$ \\
\hline & Total & $\ldots$ & 330 & 171 \\
\hline
\end{tabular}

It will be seen from Table 2 that seven infants regained their birth weight by the fourth day, or 
never lost it. All of these were small babies, three being immature, three weighing under $6 \frac{1}{2} \mathrm{lb}$. and the seventh under $7 \mathrm{lb}$. At the other end of the scale 35 infants were still below their birth weight on the twentieth day; the probable reasons for these slow starters were as follows:

\begin{tabular}{|c|c|c|c|}
\hline Underfeeding & .. & $\cdots$ & . \\
\hline Twins & . & .. & . \\
\hline Prematurity & . & . & . \\
\hline Caesarean birth & .. & . & . \\
\hline Cerebral irritation & . & . & . \\
\hline Cephalhaematoma & . & . & . \\
\hline Neonatal infections & & . & .. \\
\hline Vomiting $\quad .$. & . & . & .. \\
\hline $\begin{array}{l}\text { Anaemia } \\
\text { Not known }\end{array}$ & . & .. & . \\
\hline Not known .. & . & $\cdots$ & . \\
\hline Total & . & . & . \\
\hline
\end{tabular}

The responsibility for the slow start of these infants is therefore equally divided between feeding and other difficulties.

The daily rate of gain between the date when the birth weight was regained and the date of the first interview was calculated for each infant and recorded to the nearest one-fifth of one ounce. The results are shown graphically in Fig. 1.

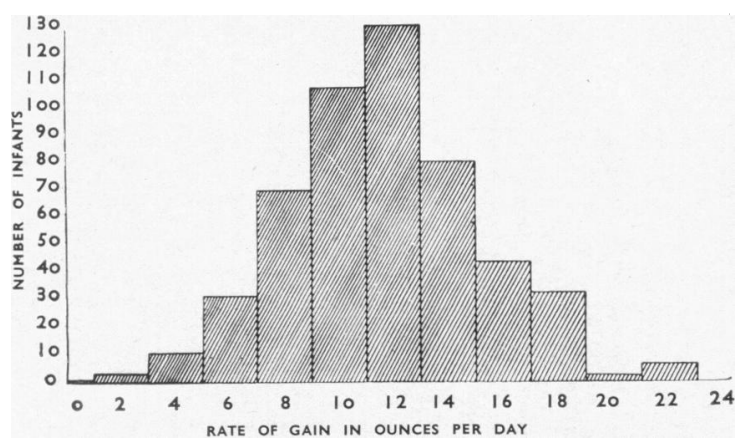

FIG. 1.-Rate of gain for the whole series of 503 infants from the day the birth weight was regained to the follow-up interview in the second month.

No less than $32 \%$ of the whole group had gained more than $1 \cdot 3 \mathrm{oz}$. daily, i.e. over $9 \mathrm{oz}$. a week. There were 14 infants who had gained $0.5 \mathrm{oz}$. or less daily, and four of these slow gainers were also slow starters as defined above; nine of the remainder were underfed and one had had pertussis. At the other end of Fig. 1 there were eight infants who had gained 2 or more oz. daily; five of these were breast fed at the first interview, two were receiving complementary feeds and one had been bottle fed for three weeks. Weight curves of three of these infants will be shown in Fig. 2 and discussed later.

Owing to the method of calculation of these average daily rates of gain and the fact that the duration of the period of calculation varied from two to seven weeks, it is not advisable to think in terms of a mean rate of gain as this might be (and often is) taken as implying a uniform rate for each infant during the first two months of life. Instead, emphasis will be laid upon the distribution of rates of gain between five broad groups. This method has been used in Table 3 where the daily rate of gain has been tabulated against the birth weight.

TABLE 3

RATE OF GaIN BY BiRTH WeIGHT IN 503 INFANTS

\begin{tabular}{|c|c|c|c|c|c|}
\hline \multirow{3}{*}{$\begin{array}{c}\text { Birth Weight } \\
\text { (lb.) }\end{array}$} & \multicolumn{5}{|c|}{ Numbers of Infants } \\
\hline & \multicolumn{5}{|c|}{ Rate of Gain (oz./day) } \\
\hline & $0-0.9$ & $-1 \cdot 1$ & $-1 \cdot 3$ & $-1 \cdot 5$ & Over 1.5 \\
\hline \multirow[t]{2}{*}{$\begin{array}{c}0-4 \frac{1}{2} \\
-6 \\
-7 \frac{1}{2} \\
-9^{2} \\
\text { Over } 9\end{array}$} & $\begin{array}{r}3 \\
16 \\
54 \\
34 \\
5\end{array}$ & $\begin{array}{r}1 \\
13 \\
52 \\
34 \\
5\end{array}$ & $\begin{array}{r}4 \\
15 \\
58 \\
42 \\
8\end{array}$ & $\begin{array}{r}1 \\
9 \\
39 \\
27 \\
2\end{array}$ & $\begin{array}{r}\overline{13} \\
39 \\
25 \\
4\end{array}$ \\
\hline & 112 & 105 & 127 & 78 & 81 \\
\hline
\end{tabular}

The birth weights of the whole group ranged from $3 \frac{1}{2}$ to $10 \frac{1}{2} \mathrm{lb}$., and 40 infants $(8 \%)$ weighed $5 \frac{1}{2} \mathrm{lb}$. or under. Table 3 shows that the average daily rate of gain is largely independent of the birth weight.

\section{Rate of Gain of a Selected Group}

The total series of 503 infants naturally comprises a number who have had temporary setbacks due to illness and feeding difficulties. An attempt has been made to single out all such infants in order to leave a residual group of satisfied infants who, so far as one can tell, have had a smooth passage since birth. The following groups have therefore been extracted: (1) Late starters, i.e. those who failed to regain their birth weight by the fifteenth day. (2) Infants who had been diagnosed as overfed since leaving the ward (except where this diagnosis had been made solely on the basis of a higher than average gain in weight). There were 71 infants in this group but retrospective appraisal suggested that true overfeeding had only occurred in six. (3) Infants with a past history of underfeeding: there were 122 in this group, but the total (84) shown in Table 4 is less because nine had also been diagnosed as overfed and 29 were included as late starters.

The remaining infants have been classified according to whether they were satisfied or not when first seen, and the 214 in the satisfied group are taken to be a normal collection of healthy, well-fed infants. Their rate of gain, and that of the remainder of the series of infants is shown in Table 4.

Examination of Table 4 reveals many interesting features. The first column gives the distribution of the rate of gain of the 214 'normal' infants; the 
TABLE 4

RATE OF GAIN FOR ' NORMAL' AND OTHER INFANTS (503 INFANTS)

\begin{tabular}{|c|c|c|c|c|c|c|c|}
\hline \multirow[b]{3}{*}{$\begin{array}{c}\text { Rate of } \\
\text { Gain } \\
\text { (oz./day) }\end{array}$} & \multicolumn{7}{|c|}{ Numbers of Infants } \\
\hline & \multicolumn{4}{|c|}{ 'Normal' Infants } & \multirow{2}{*}{$\begin{array}{c}\text { Late } \\
\text { Starters }\end{array}$} & \multicolumn{2}{|c|}{$\begin{array}{c}\text { Infants with } \\
\text { History of }\end{array}$} \\
\hline & $\begin{array}{l}\text { Satis- } \\
\text { fied }\end{array}$ & $\begin{array}{c}\text { Not } \\
\text { Satis- } \\
\text { fied }\end{array}$ & $\begin{array}{l}\text { Doubt- } \\
\text { ful }\end{array}$ & Total & & $\begin{array}{l}\text { Over- } \\
\text { feed- } \\
\text { ing } \dagger\end{array}$ & $\begin{array}{l}\text { Under- } \\
\text { feed- } \\
\text { ing }\end{array}$ \\
\hline $\begin{array}{r}0-0.9 \\
-1.1 \\
-1.3 \\
-1.5 \\
\text { Over } 1.5\end{array}$ & $\begin{array}{l}29 \\
40 \\
63 \\
42 \\
40\end{array}$ & $\begin{array}{r}16 \\
16 \\
15 \\
4 \\
6\end{array}$ & $\begin{array}{l}2 \\
4 \\
6 \\
2 \\
2\end{array}$ & $\begin{array}{l}47 \\
60 \\
84 \\
48 \\
48\end{array}$ & $\begin{array}{l}29 \\
18 \\
15 \\
10 \\
19\end{array}$ & $\begin{array}{r}7 \\
5 \\
15 \\
12 \\
2\end{array}$ & $\begin{array}{r}29 \\
22 \\
13 \\
8 \\
12\end{array}$ \\
\hline Total & 214 & 57 & 16 & 287 & 91 & 41 & 84 \\
\hline
\end{tabular}

* Infants who did not regain their birth weight by the fifteenth day. Some with a past history of over- or under-feeding are included.

+ Includes nine infants with a past history of over- and underfeeding and excludes 19 infants diagnosed overfed solely on the basis of excessive gain or intake.

median rate approaches $1 \cdot 3$ oz. per day ( 9 oz. per week). It seems certain, however, that this figure is too low, for the 29 infants gaining less than $10 z$. daily may well include a number with an unrecognized past history of underfeeding. Indirect evidence is provided by the fact that $50 \%$ of these infants were bottle fed, whereas for the over $1.5 \mathrm{oz}$. daily group only $12 \%$ had had to give up breast feeding. Nevertheless some of these 29 infants must presumably be normal and destined to grow slowly during infancy at least. By the same token, $12 \%$ of the ' normal' satisfied infants were receiving complementary feeds, and although no definite diagnosis of underfeeding had been made in these cases, no doubt in many a short period of underfeeding at the breast had occurred before bottle feeds were added.

The ratio between the satisfied and unsatisfied columns of ' normal' infants is also interesting; - in the lowest rate of gain group it is $2: 1$, rising steadily to $10: 1$ in the up to $1.5 \mathrm{oz}$. daily group. This is further evidence that a considerable proportion of the lowest rate of gain group consists of unrecognized underfed infants. It is difficult to know where to draw the dividing line between underfed and unsatisfied infants, but for practical purposes those gaining less than $1 \mathrm{oz}$. daily have been regarded as underfed, and those gaining more as unsatisfied, but this is purely arbitrary and apt to be misleading. On the other hand, to refer to a lusty infant gaining at the highest rates as underfed may appear somewhat incongruous.

In the three columns of infants with abnormal feeding histories shown in Table 4 there is on the whole a low rate of gain amongst late starters and those with a past history of underfeeding (many were still not satisfied when first seen), and a normal distribution amongst the group with a history of reputed overfeeding. This latter finding is not surprising as the diagnosis was frequently erroneous.
To sum up, comparison of the ' normal' satisfied group of 214 infants with the remainder of the total group of 503 infants shows that $68 \%$ of the former gained $1 \cdot 1 \mathrm{oz}$. or more daily whereas only $49 \%$ of the latter had done so. The difference between the two groups is considerable and must be regarded as partly the responsibility of the infant welfare clinics where the majority of the mothers had already sought advice. It is impossible to escape the conclusion that underfeeding frequently goes unrecognized at these clinics and sometimes even gets mistaken for overfeeding with the result that many infants are prevented from fulfilling their desire to gain weight at the optimum rate. It is only fair to add that this failure to recognize underfeeding also occurs in hospitals where Wood (1952) has recently appreciated that many babies admitted for vomiting of unknown origin are really simply underfed.

Perhaps the most interesting fact to be gleaned from Table 4 is that although the original series has been whittled down from 503 to 214 it is perfectly clear that this group still contains a number of previously and actually underfed babies. The progress of approximately $60 \%$ of the original group had therefore been checked before the second month of life was concluded.

\section{Optimal Rate of Gain}

The objection to laying undue emphasis on a median rate of gain for a heterogeneous group of infants is obvious, but there is also a danger that the recognition of an average for a healthy selected group will be used by others to level down those infants able to do better for fear of overfeeding them.

For this reason three infants have been selected whose early rate of gain exemplifies the ideal to be aimed at; their weight curves for the first six months of life are shown in Fig. 2. All three are male breast-fed babies showing a rate of gain of $16 \mathrm{oz}$. per week from the second to the seventh week.

This rapid rate of gain in the early weeks, which will be referred to here as the ' stoking-up' process, goes largely unrecognized as a normal feature in the human infant and yet in other mammals it is of well known occurrence and is perhaps best exemplified by the grey seal which doubles its birth weight in the first fortnight of life (Amoroso, Goffin, Halley, Matthews and Mathews 1950). All three infants depicted in Fig. 2 have been followed well into their second year and none has suffered from bronchitis or pneumonia or experienced any feeding difficulties, yet in the early weeks two had been diagnosed as overfed. Their weights at 6 months fell between $19 \frac{1}{2}$ and $20 \frac{1}{2} \mathrm{lb}$., and at 1 year they had all increased to between 


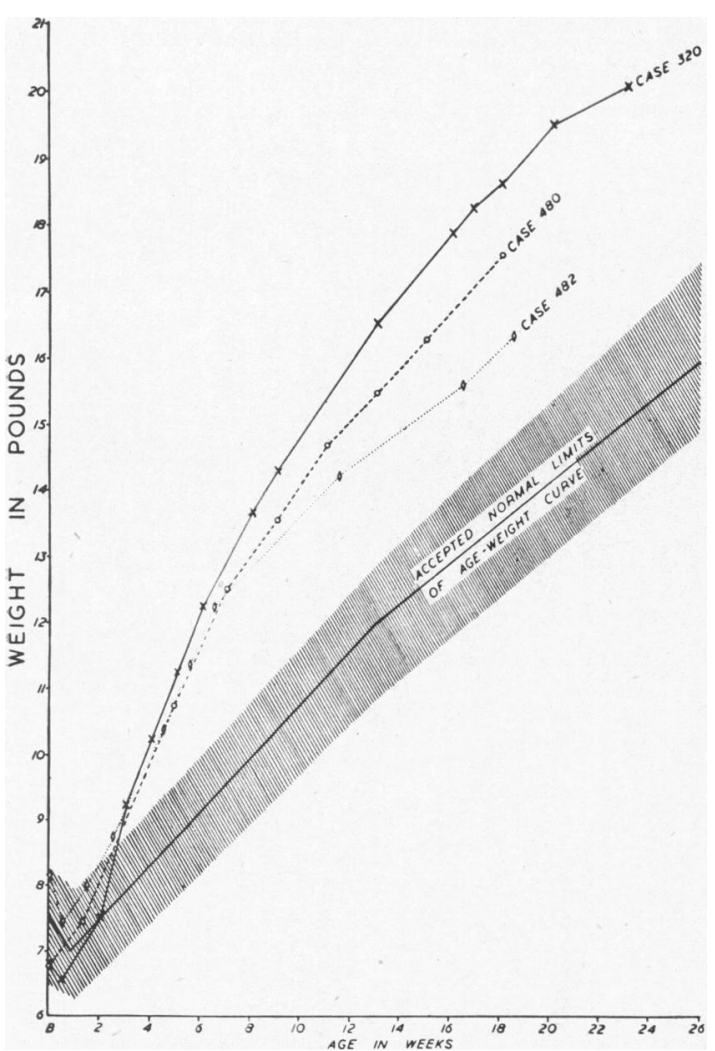

FIG. 2.-Optimal growth curves of three healthy contented breast fed babies illustrating the 'stoking-up' process between the second and sixth weeks.

25 and $26 \mathrm{lb}$., which represents a steady gain of $3 \mathrm{oz}$. per week, i.e. less than one-fifth of that in the first three months.

It is not intended to assert that all infants would gain at the optimal rate depicted here even if given the opportunity, but a strong impression was gained that those who have the potentiality so to do are commonly found amongst infants with feeding problems at this age. These babies, when restricted, commonly cry and vomit. If the gain is above average, overfeeding is often suspected, if gaining normally, wind is usually diagnosed, whereas only if the gain is low is the true nature of the difficulty appreciated. Presumably many of the unsatisfied infants would have been contented if the feeds in the early weeks had been adequate to allow for some degree of 'stoking-up'. Premature babies are expected to require additional nourishment in this period, but for some reason medical men have little confidence in the full term infant's natural appetite as a measure of the amount of milk he requires. Mothers, on the other hand, frequently affirm that their babies know when they have had enough and those who are guided by this principle succeed very well in practice.

\section{Overfeeding}

The final decision for or against self-regulated feeding must depend upon whether or not overfeeding is either common or a matter of concern. It has already been mentioned how frequently this diagnosis had been made or hinted at in the infant welfare clinics and how rarely it stood the test of retrospective enquiry. Of the 71 infants in whom a definite diagnosis of overfeeding had been made, in only six did subsequent events support the diagnosis, and in five of these it had been due to wakening the babies for three-hourly feeds-a situation which would never have arisen on a self-demand regime. The sixth infant ceased vomiting when given one breast instead of two, but at no time was there any cause for alarm about his condition. In a further 59 cases the mother had been warned against overfeeding, and thus $26 \%$ of the whole group had been suspected of being overfed before they were 2 months old. A more detailed study of the causes of the diagnostic errors has been made elsewhere (Wickes, 1951), but it must be mentioned that the majority of these babies were healthy breast fed infants whose only fault was a rate of gain of more than $1 \mathrm{oz}$. daily. The reduction in quantity had been enforced to make the infant comply with a standard which is, after all, merely an average figure and in any case it is manifestly too low. One may conclude that a morbid fear of overfeeding is prevalent. It springs from the days when gastro-enteritis was the scourge of infancy but it is out of harmony with present-day conditions.

\section{Importance of the 'Stoking-up' Process}

Failure to recognize the 'stoking-up' process has important consequences for the infant as it is one of the main factors responsible for the prevalence of underfeeding in the early weeks.

In the case of the breast fed baby the extra demand for nourishment falls at a time when lactation is commonly precarious. The causes of hypogalactia cannot be discussed here; it is usually considered that failure at this time is due to the fact that the mother has had to resume her household duties, but it must be emphasized that failure is relative and the demands of the infant are probably an equally important contributory cause. If the baby seems hungry and yet is receiving the calculated quantity based upon the results of test weighing and the use of the standard formula, then there is a tendency for the breast milk to be described as ' too weak', or to say that it 'didn't agree with him'. If on the other hand the gain is below 
average complementary feeds are added but the quantity recommended is usually fixed and inadequate. That complementary feeding so managed yields poor results is shown by the fact that in this series $50 \%$ of those mothers who embarked upon it abandoned the breast altogether within one week of starting the bottle, and only $25 \%$ maintained the combined method for more than three weeks. Only eight babies were able to revert to full breast feeding after the combined method had been begun.

In the case of the bottle fed baby, the graded instructions on the packets of dried milk clearly show that the 'stoking-up' process is not catered for. Indeed in most cases the recommended quantity is even less than the standard formula allows (50 cals. per lb. expected body weight). Recently, however, one manufacturer has increased all the feeds by one level scoop which means that the smallest feeds of two scoops are augmented by $50 \%$ (in the descriptive pamphlet this is modestly referred to as ' a little more ', no doubt for fear of being accused of overfeeding). This is a step in the right direction as the younger babies receive proportionately more, but there is still a long way to go.

The whole difficulty revolves around the wide acceptance of the formula ' $2 \frac{1}{2} \mathrm{oz}$. per lb. expected body weight per 24 hours'. This formula is incompatible with the demands of most infants during the first two months of life for the following reasons: (1) It assumes and requires a rate of gain of only $1 \mathrm{oz}$. daily. (2) It endeavours to standardize all infants to a straight-line weight chart regardless of the steep rise in the early weeks. (3) It assumes a uniform appetite from feed to feed. (4) It suggests that all infants should gain at the same rate on a given intake.

Fig. 3 illustrates some of these shortcomings and is derived from the case history of an artificially fed baby on a self-regulated intake. Initially the intake exceeded the standard quantity and it is at this stage that unsatisfied hunger is so common. If, however, enough nourishment has been supplied, the subsequent intake tends to fall below the calculated quantity and for only a brief period, where the lines in the diagram intercept, will the standard formula be appropriate. Gesell and Ilg (1937) publish a similar case on a steady self-regulated intake from the fourth to the twelfth week, and Evans and Mac Keith (1951) print a chart of a breast fed baby with a level intake over the same period.

Nowadays mothers with a copious supply of breast milk show the best results, partly because full breast feeding is not readily amenable to the imposition of restrictions, yet isolated test feeds in

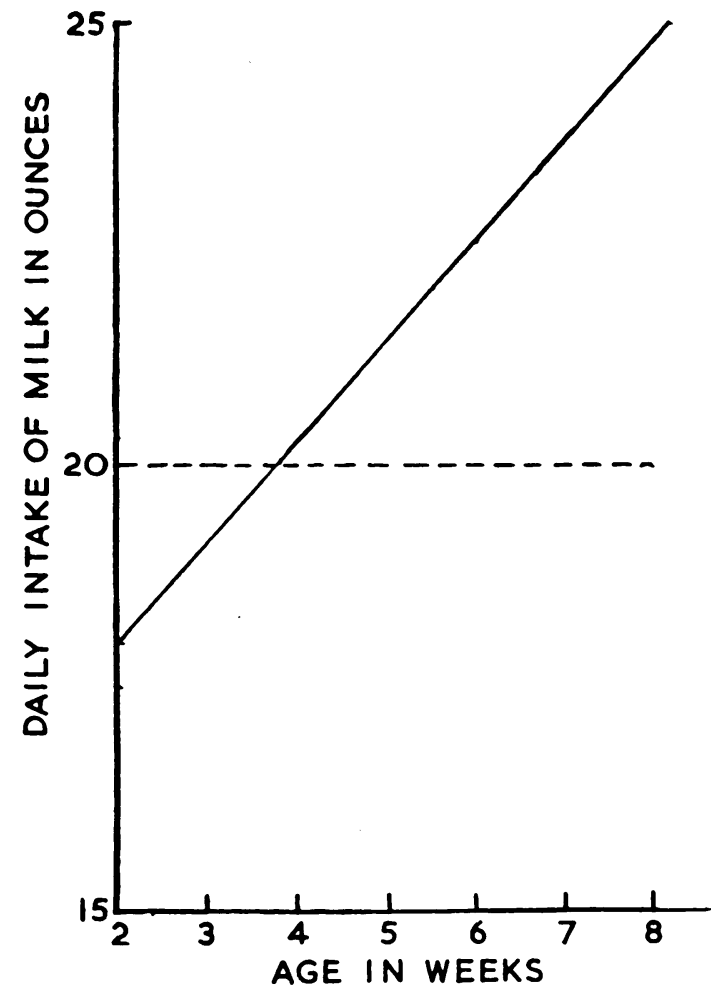

Fig. 3.-Diagram to illustrate some of the deficiencies in the standard feeding formula ( $2 \frac{1}{2} \mathrm{oz}$./lb. expected body weight per 24 hours). Continuous line represents the accepted daily intake for a baby weighing $7 \mathrm{lb}$. at birth and increasing by $1 \mathrm{oz}$. daily after the second week. Interrupted line represents the actual intake demanded. At only one point, where the lines intercept, is the standard formula appropriate.

the thriving infant often show intakes which, to the uninitiated, may cause unnecessary alarm.

\section{Satiation}

An infant was recorded as 'satisfied' solely on the basis of contentment with his present feeds. This method avoided the difficulty which arises over classifying those infants who remain hungry in spite of a 'good' rate of gain, or a supposedly adequate intake. At the follow-up interview each mother was asked whether her baby was satisfied with his feeds; if she considered she had plenty of breast milk, or if her infant was receiving dried milk in accordance with the instructions, she was apt to reply in the affirmative, meaning ' he ought to be '. In cases of doubt, therefore, a second question was put: 'If your baby could talk, would he say he was getting enough to eat?' The questions framed in this way did not therefore include those whose underfeeding had already been successfully treated. The impression that so many babies would have 
answered so forcibly in the negative constitutes a potent adverse criticism of the present day vogue for restrictive feeding. So often one was told that the welfare clinic had been 'satisfied' though the baby clearly was not, that as he was receiving the calculated quantity ' he must be having enough'. His uneasy cries said otherwise.

Table 5 shows the numbers of infants found to be satisfied, not satisfied or doubtful, analysed by the method of feeding and separated into first and later babies.

TABLE 5

SATiation by Method of Feeding at First INTERView (503 INfants)

\begin{tabular}{|c|c|c|c|c|}
\hline & \multicolumn{4}{|c|}{ Number of Infants (percentages in brackets) } \\
\hline & Satisfied & $\begin{array}{c}\text { Not } \\
\text { Satisfied }\end{array}$ & Doubtful & Total \\
\hline $\begin{array}{l}\text { First Babies } \\
\text { Breast only } \\
\text { Breast + bottle } \\
\text { Bottle only }\end{array}$ & $\begin{array}{r}152(70) \\
29(63) \\
57(53)\end{array}$ & $\begin{array}{l}41(19) \\
16(35) \\
38(35)\end{array}$ & $\begin{array}{c}23(11) \\
1(2) \\
13(12)\end{array}$ & $\begin{array}{r}216(100) \\
46(100) \\
108(100)\end{array}$ \\
\hline Total & 238 & 95 & 37 & 370 \\
\hline $\begin{array}{l}\text { Other Babies } \\
\text { Breast only } \\
\text { Breast + bottle } \\
\text { Bottle only }\end{array}$ & $\begin{array}{l}47(77) \\
10(45) \\
34(68)\end{array}$ & $\begin{array}{r}9(15) \\
12(55) \\
15(30)\end{array}$ & $\begin{array}{l}5(8) \\
0(0) \\
1 \text { (2) }\end{array}$ & $\begin{array}{l}61(100) \\
22(100) \\
50(100)\end{array}$ \\
\hline Total & 91 & 36 & 6 & 133 \\
\hline
\end{tabular}

The group labelled 'doubtfully satisfied' (43 infants) on closer scrutiny may be subdivided as follows:

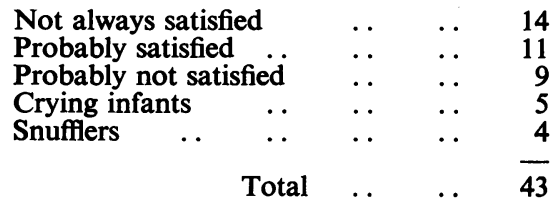

It is noteworthy that whereas $10 \%$ of the first babies. were 'doubtful', less than $5 \%$ of the others were so classified; this no doubt reflects the greater experience and confidence of the mothers of the latter group.

Examination of Table 5 as a whole shows that infants of later birth orders were satisfied more commonly than first babies, and breast fed infants more often than those artificially fed. For the whole group of 503 infants, approximately $65 \%$ were satisfied, but of the 158 in the wholly bottle fed group only $57 \%$ were satiated. Thus, in spite of the fact that nearly half the mothers had already abandoned breast feeding, those who were succeeding were more likely to own satisfied babies than those who had resorted entirely to the bottle. The reasons for this have already been given. Again, the fact that the multiparae were more likely to have satisfied bottle fed babies suggests that past experience had led them to supersede the recommended quantities.

Although most of the infants had already attended an infant welfare clinic (the whole series had been spread amongst 92 clinics in Greater London), about one-third were still definitely hungry. Nor does this fraction give full value to the discrepancy as many mothers attributed the symptoms of unsatisfied hunger (crying and vomiting) to ' wind'. Thus $50 \%$ of all satisfied infants were stated by their mothers to suffer excessively from ' wind', compared with no less than $75 \%$ of the unsatisfied group. Over $80 \%$ of the whole series had been given gripe water, often in the mistaken belief that ' wind' rather than hunger was the cause of their symptoms. A self-demand regime would have improved the lot of these babies more satisfactorily than the administration of gripe water or sodium citrate tablets.

\section{Conclusion}

Analysis of this series of healthy infants leaves little doubt that the practice of infant feeding today underestimates the requirements of the young baby. Underfeeding is extremely prevalent and springs from several causes including inadequate lactation, the use of an inappropriate formula for calculating feeds, ignorance of the optimal rate and curve of growth and a morbid fear of overfeeding in the early weeks.

It is not known to what permanent extent underfeeding retards the physical development of the growing infant. It is possible that towards the end of the first six months the setbacks of the earlier period will have been eradicated. On the other hand it has been shown in sheep by Hammond (quoted by Huggett, 1946) that bone grows first, then muscle and finally fat. Thus, if nutrition is temporarily deficient, the recuperative powers are limited mainly to those tissues whose optimal growth occurs during the period of adequate feeding. No data on this important point are available for the human infant but it seems likely that the same principle would apply.

It also seems likely that, from the psychological standpoint, underfeeding in the early weeks may have far-reaching consequences. The human infant at this time regards the attainment of food as a matter of life and death and his whole emotional framework is tuned to this vital function. It is to be expected, therefore, that any frustration here would strike at the very foundations of his psychic security. In this respect he is particularly vulnerable by reason of his lack of mobility, but the emotional storm which he displays, if judged by adult standards, would be regarded as little short of mania. It has been argued that since modern life is so full of frustrations and restrictions the sooner the neonate 
begins training for them the better, but this argument is too sophisticated for one so young, and in any case to follow it to its logical conclusion a return to tight swaddling would have to be advocated. Whatever opinions are finally adopted, it is apparent that this is a fundamental problem of great importance; proof of its continuing influence into adult life may perhaps be found in the dogmatic views so often expressed by medical men and women upon the problems of infant feeding.

\section{Summary}

A consecutive series of 503 healthy infants born in hospital to 366 primiparae and 125 multiparae has been seen at a follow-up clinic during the second month of life, and the feeding history to date has been described.

The rate of gain in weight for the whole group has been determined for the period between the date of regaining the birth weight and the first interview at the follow-up clinic.

A group of 214 satisfied infants with an unblemished feeding history has been extracted from the main series. The progress of the remainder (57\% of the original series) has therefore been checked, usually by underfeeding, before the end of the second month.

Sixty-eight per cent. of the selected group gained $1 \cdot 1 \mathrm{oz}$. or more daily compared with $49 \%$ of the remainder.

The median rate for healthy infants in the first two months approaches 9 oz. per week.

The optimal rate of gain for this age period is approximately $16 \mathrm{oz}$. per week.

The conception of a 'stoking-up' process in the early weeks has been introduced and exemplified by the weight curves of three healthy breast fed babies.
The standard formula for calculating infants' feeds is inappropriate for this age group.

Objective evidence of the failure of orthodox methods has been provided by studying satiation; only $57 \%$ of the artificially fed infants were satisfied with their feeds.

A morbid fear of overfeeding, which had been suspected in $26 \%$ of the series, is largely responsible for results which, from the infants' point of view, may permanently hamper their development.

This investigation, which formed part of an M.D. thesis for the University of Cambridge, was carried out while holding the position of Chief Assistant to the Children's Department, St. Bartholomew's Hospital. It is a great pleasure to record my thanks to Dr. Charles F. Harris and Dr. A. White Franklin for all their help and instruction. I am also indebted to Mr. M. P. Curwen, statistician, for his help with the tables and to Mr. N. K. Harrison, of the photographic department, for the figures.

\section{REFERENCES}

Amoroso, E. C., Goffin A. Halley, G. Matthews, L. H and Mathews, 'D. J. (1950). (Proceedings of the Physiological Society.) J. Physiol., $1134 \mathrm{P}$

Boyd, J. D. (1948). Amer. J. Dis. Child., 76, 53.

Collis, W. R. F. (1948). Modern Methods of Infant Management. London.

Evans, P. R. and Mac Keith, R. (1951). Infant Feeding and Feeding Difficulties. London.

Feldman, W. M. (1927). The Principles of Ante-natal and Post-natal Child Hygiene. London.

Gesell, A. and Ilg, F. L. (1937). Feeding Behavior of Infants, p. 106. Philadelphia.

Gore, A. T. and Palmer, W. T. (1949). Lancet, 1, 385.

Harris, W. (1689). 'De morbis acutis infantum;'An Exact Enquiry into, and Cure of the Acute Diseases of Infants, by W. Harris, Englished by W. Cockburn. London, S. Clement. 1693.

Huggett, A. St G. (1946). Brit. med. Bull., 4, 196.

Hutchison, R. (1944). Lectures on Diseases of Children, 9th ed., rev. by A. Moncrieff, p. 13. London.

Illingworth, R. S. (1949). Brit. med. J., 2, 1077.

Morris, N. (1947). In Garrod, Batten and Thursfield's Diseases of Children, 4th ed., ed. Paterson, D. and Moncrieff, A. A. vol. 1, p. 61 . London.

Sontag, L. W. and Reynolds, E. L. (1945). J. Pediat., 26. 327.

Spock, B. (1946). The Common Sense Book of Baby and Child Care, p. 107. New York.

Wickes, I. G. (1951). Infant Feeding to the Second Month. M.D. Thesis, University of Cambridge.

Wood, B. S. B. (1952). Lancet, 1, 28. 